Gulawentah: Jurnal Studi Sosial

ISSN 2528-6293 (Print); ISSN 2528-6871 (Online)

Vol. 4, No. 1, Juli 2019, Hal 13-20

Tersedia Online: http://e-journal.unipma.ac.id/index.php/gulawentah

\title{
Dampak Pembangunan Srambang Park Ngawi Terhadap Kehidupan Ekonomi Masyarakat Dan Potensinya Sebagai Sumber Materi Pembelajaran IPS SD
}

\author{
Dian Larasati \\ Magister Pendidikan Ilmu Pengetahuan Sosial, Universitas PGRI Madiun, Indonesia \\ Email: dianlarasati251993@gmail.com
}

\begin{abstract}
Abstrak
Penelitian ini bertujuan untuk mendeskripsikan dan menganalisis dampak pembangunan Srambang Park Ngawi terhadap kehidupan ekonomi masyarakat dan potensinya sebagai sumber materi pembelajaran IPS SD.Penelitian ini merupakan penelitian kualitatif yang dilakukan pada bulan Maret 2018 hingga Maret 2019. Penelitian berlokasi di Desa Girimulyo Kecamatan Jogorogo Kabupaten Ngawi dengan mengambil obyek wisata Srambang Park Ngawi. Sumber data primer yang digunakan dalam penelitian ini adalah Kepala Desa Girimulyo, manajer obyek wisata Srambang Park Ngawi dan masyarakat yang bertempat tinggal serta melakukan kegiatan ekonomi di sekitar obyek wisata. Sumber data sekunder yang digunakan dalam penelitian ini adalah dokumen dan profil tentang jumlah penduduk, pekerjaan, dan tindakan yang dilakukan masyarakat terhadap adanya obyek wisata Srambang Park Ngawi yang berada di Desa Grimulyo Kecamatan Jogorogo, berita di media massa, serta data lain yang relevan. Adapun teknik pengumpulan data yang digunakan meliputi observasi, wawancara, dan dokumentasi. Kemudian data dianalisis dengan menggunakan analisis deskriptif kualitatif.Analisis penelitian menunjukkan bahwa pembangunan obyek wisata Srambang Park Ngawi memberikan dampak positif terhadap kehidupan ekonomi masyarakat. Sebelum pembangunan wisata Srambang Park Ngawi, sebagian besar masyarakat bekerja sebagai petani, namun sesudah adanya pembangunan obyek wisata kehidupan ekonomi masyarakat meningkat. Masyarakat mendapat pekerjaan tambahan sebagai pedagang makanan dan minuman serta penyedia jasa berupa fasilitas yang disewakan untuk wisatawan seperti tempat parkir, ojek wisata dan kamar mandi. Selain itu, pembangunan obyek wisata juga berdampak pada pendapatan masyarakat, dimana sebelum pembangunan obyek wisata Srambang Park Ngawi tingkat pendapatan responden masih tergolong rendah. Sesudah adanya pembangunan obyek wisata Srambang Park Ngawi pendapatan responden mengalami peningkatan. Hasil penelitian yang diperoleh juga menunjukkan bahwa kehidupan ekonomi masyarakat di obyek wisata Srambang Park Ngawi memiliki potensi sebagai sumber materi pembelajaran IPS SD.
\end{abstract}

Kata kunci: Srambang Park Ngawi; Ekonomi Masyarakat; Sumber Belajar IPS

\section{The Impact of Srambang Park Ngawi Development on The Economic Society Life and The Potential as a Source of Learning Social Materials in Elementary School}

\begin{abstract}
This study aims to describe and analyze the impact of srambang park ngawi development on the economic society life and the potential as a source of learning social materials in elementary school.This research is a qualitative research conducted in March 2018 until March 2019. The research is located in Girimulyo Village, Jogorogo Sub-District, Ngawi Regency by taking tourism objects Srambang Park Ngawi. The primary data sources used the Chief of Girimulyo village, the tourism manager of Srambang Park Ngawi and the people who live and carry out the economic activities around tourism objects. Secondary data sources used are documents and profiles of populations, occupations, and actions taken by the society towards the existence of tourism objects
\end{abstract}

DOI: 10.25273 /gulawentah.v4i1.4864

Copyright (C) 2019 Universitas PGRI Madiun

All rights reserved. 
Srambang Park Ngawi located in Grimulyo Village, Jogorogo District, also news in the mass media, with the relevant data. The data collection techniques used observations, interviews, and documentations. Then the data were analyzed using qualitative descriptive analysis. The analysis of the research shows that Srambang Park Ngawi development of tourism objects has a positive impact on the economic society life. Before tourism Srambang Park Ngawi development, most people worked as a farmers, but after that the economic society life is increased. People get jobsides as food and beverage traders and service providers of facilities which rented out to tourists such as parking area, motorcycle, taxis and bathrooms. Besides that, the development of tourism objects also has an impact on people's income, where before the construction of tourism objects Srambang Park Ngawi the income was still relatively low. Whereas, after the construction of tourism objects Srambang Park Ngawi get the income increased. As the results, this research showed that the economic society life of tourism objects in Srambang Park Ngawi has the potential as a source of learning social materials in elementary school.

Keywords: Srambang Park Ngawi; The Economic Society; Social Resources

\section{Pendahuluan}

Kabupaten Ngawi terletak di wilayah barat Provinsi Jawa Timur yang berbatasan langsung dengan Provinsi Jawa Tengah dimana secara geografis Kabupaten Ngawi terletak pada posisi 110o10'-111040' Bujur Timur dan 7o21'-7o31' Lintang Selatan. Luas wilayah Kabupaten Ngawi adalah 1.295,58 km2, dimana sekitar 39 persen atau sekitar 504,76 km2 berupa lahan sawah. Sesuai dengan Peraturan Daerah (Perda) Kabupaten Ngawi tahun 2004, secara administrasi wilayah ini terbagi ke dalam 19 kecamatan dan 217 desa, dimana 4 dari 217 desa tersebut adalah kelurahan. Topografi wilayah Kabupaten Ngawi berupa dataran tinggi dan tanah datar. Tercatat ada 4 kecamatan terletak pada dataran tinggi yaitu Sine, Ngrambe, Jogorogo dan Kendal yang terletak di kaki Gunung Lawu (Lestari, 2014).

Ngawi memiliki banyak potensi alam yang luar biasa dan banyak dijadikan sebagai tujuan pariwisata. Pariwisata adalah salah satu sektor yang merupakan sumber penerimaan negara. Tidak hanya itu, sektor pariwisata juga merupakan suatu kegiatan ekonomi memiliki mata rantai yang sangat panjang. Keberadaan sektor pariwisata dapat memberi manfaat positif bagi pemerintah, pihak swasta dan masyarakat yang ikut terlibat dalam memanfaatkan peluang usaha di objek wisata. Manfaat yang dapat diperoleh pemerintah dari sektor pariwisata seperti sumber penerimaan devisa dan pajak. Selain itu, sektor pariwisata menciptakan peluang usaha yang dapat dimanfaatkan oleh pihak swasta untuk melakukan kegiatan ekonomi seperti usaha rumah makan, hotel dan sarana transportasi. Tidak hanya itu, pariwisata juga mampu meningkatkan pendapatan masyarakat yang ikut terlibat langsung dalam sektor pariwisata.

Salah satu daerah tujuan pariwisata di kabupaten Ngawi adalah Desa Girimulyo Kecamatan Jogorogo yang terdapat kawasan hutan dan air terjun. Penduduk sekitar menamainya dengan Srambang. Sudah cukup lama masyarakat mengenal kawasan Srambang ini sebagai tempat wisata untuk melepas penat, menghabiskan waktu liburan dengan menikmati panorama alam yang sangat mempesona. Bagi pelajar Srambang sering digunakan untuk kegiatan perkemahan. Sejak pertama kali dikenal masyarakat dan dijadikan tujuan wisata kawasan ini masih belum dilengkapi dengan fasilitas yang memadai. Namun, dengan berjalannya waktu dan adanya perhatian dari pemerintah daerah, pihak swasta, dan masyarakat sekitar akhirnya Srambang mulai dibangun dan diresmikan oleh Bupati Ngawi Ir. Budi Sulistyono pada hari Selasa, 19 Desember 2017 dengan wajah dan nama baru yaitu Srambang Park Ngawi.

Pariwisata Kabupaten Ngawi memiliki objekwisata alam dan wisata budaya yang menarik dan berpotensi untuk dikembangkan (Trilaksana, 2014). Srambang Park Ngawi adalah area wisata 
yang mengunggulkan konsep taman hutan asri dan air terjun. Letaknya yang berada di kaki Gunung Lawu membuat udaranya sangat sejuk. Untuk mencapai lokasi dapat dengan meggunakan kendaran bermotor sekitar 45 menit dari pusat kota Ngawi. Srambang Park Ngawi dilengkapi oleh berbagai fasilitas, diantaranya area parkir yang luas, toilet, kamar mandi, mushola, gazebo, tempat berfoto dan rumah makan. Sebelum dibangunnya kawasan Srambang menjadi tempat wisata baru umumnya masyarakat sekitar berprofesi sebagai: petani, berkebun, beternak, ibu rumah tangga, dan menjadi buruh atau karyawan ke kota. Setelah Srambang Park Ngawi dibangun harapannya masyarakat sekitar dapat meningkatkan kehidupan perekonomiannya mengingat pariwisata mendatangkan devisa yang banyak.

Banyaknya pengunjung yang datang ke Srambang Park Ngawi akan membuka kesempatan berusaha bagi masyarakat sekitar untuk melakukan kegiatan dengan menyediakan berbagai macam kebutuhan wisatawan selama berada di kawasan Srambang Park Ngawi. Peluang inilah yang dimanfaatkan oleh masyarakat dengan menawarkan berbagai jasa atau barang-barang yang dibutuhkan untuk menarik minat wisatawan yang berkunjung. Adapun jenis jasa dan fasilitas yang ditawarkan masyarakat kepada wisatawan antara lain seperti tempat makan dan minum, penyewaan kamar mandi, retribusi biaya masuk atau parkir, penginapan dan lain sebagainya. Kegiatan-kegiatan tersebut tentunya berdampak pada peningkatan pendapatan masyarakat sekitar.

Sumber penghidupan masyarakat di Desa Girimulyo sebelum pembangunan obyek wisata Srambang Park Ngawi pada umumnya adalah petani. Sektor pertanian jenis komoditi yang dihasilkan adalah padi. Pembangunan kawasan wisata Srambang Park Ngawi adalah salah satu bentuk pengelolaan kawasan wisata alam yang bertujuan untuk memberikan manfaat terutama bagi perlindungan, pelestarian serta pemanfaatan potensi wisata dan jasa lingkungan sumber daya alam khususnya pada wilayah hutan lindung Perhutani KPH Lawu DS Drive Jawa Timur. Selain itu, masyarakat dapat merasakan manfaatnya secara langsung di sektor kepariwisataan melalui terbukanya lapangan usaha yang menciptakan kesempatan kerja baru serta mampu meningkatkan pendapatan bagi masyarakat.

Penyelenggaraan kepariwisataan juga ditujukan untuk meningkatkan pendapatan nasional dalam rangka meningkatkan kesejahteraan dan kemakmuran rakyat, memperluas, memeratakan kesempatan berusaha dan lapangan kerja, mendorong pembangunan daerah, memperkenalkan dan mendaya gunakan obyek dan daya tarik wisata di Indonesia serta memupuk rasa cinta tanah air dan mempercepat persahabatan antar bangsa. Pembangunan pariwisata juga mendorong dan mempercepat pertumbuhan ekonomi. Kegiatan pariwisata menciptakan permintaan, baik konsumsi maupun investasi yang pada gilirannya akan menimbulkan kegiatan produksi barang dan jasa. Selama berwisata, wisatawan akan melakukan belanja, sehingga secara langsung menimbulkan permintaan (Tourism Final Demand) pasar barang dan jasa. Selanjutnya, final demand wisatawan secara tidak langsung menimbulkan permintaan akan barang modal dan bahan baku (Investmen Derived Demand) untuk berproduksi memenuhi permintaan wisatawan akan barang dan jasa tersebut. Dalam usaha memenuhi permintaan wisatawan diperlukan investasi di bidang transportasi, komunikasi, perhotelan/penginapan, akomodasi, industri jasa, rumah makan dan lain-lain.

Sehubungan dengan pesatnya perkembangan pariwisata, pola pembangunan berkelanjutan tersebut sangat cocok diterapkan karena dapat bertujuan untuk melestarikan keberadaan pariwisata yang ada sekarang ini kepada generasi yang akan datang. Pembangunan pariwisata difokuskan pada tiga aspek utama yaitu ekonomi, sosial-budaya dan lingkungan. Sehubungan dengan hal di atas, materi pembelajaran IPS SD salah satunya membahas tentang "Kegiatan Ekonomi dalam Memanfaatkan Sumber Daya Alam". Oleh sebab itu, Srambang Park Ngawi diharapkan dapat juga 
berpotensi sebagai sumber materi pembelajaran IPS SD sekaligus dapat sebagai upaya memperkaya sumber-sumber belajar yang berkaitan dengan materi tersebut.

Dalam kegiatan pembelajaran di sekolah, peserta didik tidak hanya berinteraksi dengan tenaga pengajar sebagai salah satu sumber, tetapi mencakup interaksi dengan semua sumber belajar yang memungkinkan dipergunakan untuk mencapai hasil yang diinginkan. Pada pembelajaran IPS di SD banyak tersedia sumber belajar yang memiliki potensi untuk dimanfaatkan dalam mendukung proses belajar dan hasil pembelajaran, baik yang ada di sekolah, maupun di luar lingkungan sekolah. Dengan pembelajaran IPS di SD, peserta didik mengenal lingkungan fisik maupun lingkungan sosial, sehingga peserta didik mempunyai keperdulian dan kecintaan terhadap lingkungan sekitarnya.

Guru harus tahu dan mengenal dengan baik jenis-jenis sumber belajar yang akan digunakan, itu saja belum cukup karena disini dibutuhkan lagi kemauan dan kreatifitas guru untuk menyediakan dan mencari pengetahuan tentang cara memanfaatkan sumber belajar tersebut secara efektif dan efesien. Sumber pembelajaran IPS dapat menggunakan buku sumber (buku teks, majalah atau koran, dan media massa lainnya), media dan alat pengajaran, situasi, dan kondisi kelas serta lingkungan. Bagi guru IPS buku sumber bukan satu-satunya sumber pembelajaran yang dapat digunakan, karena buku sumber pada umumnya memuat informasi yang sudah lama. Media, alat peraga dan lingkungan dalam pengajaran merupakan sumber pembelajaran yang dapat membantu guru dalam melaksanakan perannya sebagai demonstrator (Nachrawie, 2017).

Penelitian ini bertujuan untuk mendeskripsikan dan menganalisis dampak pembangunan Srambang Park Ngawi terhadap kehidupan ekonomi masyarakat dan potensinya sebagai sumber materi pembelajaran IPS SD. Manfaat dari penelitian ini antara lain: Pemerintah Daerah khususnya Dinas Pariwisata Kabupaten Ngawi dalam merumuskan dan menetapkan kebijaksanaan untuk membangun lebih baik lagi obyek wisata Srambang Park Ngawi, Mahasiswa Program Pascasarjana dalam menambah pengetahuan tentang ilmu ekonomi kaitannya dengan pendidikan ilmu pengetahuan sosial terutama mengenai dampak pembangunan Srambang Park Ngawi terhadap kehidupan ekonomi masyarakat dan potensinya sebagai sumber materi pembelajaran IPS SD, Tenaga Pendidik SD dalam menggunakan sumber belajar mengenai dampak pembangunan Srambang Park Ngawi terhadap kehidupan ekonomi masyarakat dan bagi masyarakat dapat menjadi informasi mengenai dampak pembangunan wisata dalam mendorong kegiatan dan pertumbuhan perekonomian sekitarnya.

\section{Metode Penelitian}

Pendekatan dalam penelitian ini adalah pendekatan kualitatif. Metode penelitian kualitatif adalah metode penelitian yang berlandaskan pada filsafat postpositivisme atau enterpretif, digunakan untuk meneliti pada kondisi obyek yang alamiah, di mana peneliti adalah sebagai instrument kunci, teknik pengumpulan data dilakukan secara trianggulasi (gabungan observasi, wawancara, dokumentasi), data yang diperoleh cenderung data kualitatif, analisis data bersifat induktif/kualitatif, dan hasil penelitian kualitatif bersifat untuk memahami makna, memahami keunikan, mengkontruksi fenomena dan menemukan hipotesis (Sugiyono, 2009). Sedangkan, (Bungin, 2007, p. 68) mengungkapkan bahwa penelitian kualitatif adalah penelitian yang menggambarkan, meringkaskan berbagai kondisi, berbagai situasi, atau berbagai fenomena realitas sosial yang ada di masyarakat yang menjadi objek penelitian, dan berupaya menarik realitas itu ke permukaan sebagai sebuah ciri, karakter, sifat, model, tanda, atau gambaran tentang kondisi situasi ataupun fenomena tertentu.

Pengumpulan data pada dasarnya merupakan suatu kegiatan operasional agar tindakannya masuk pada pengertian penelitian yang sebenarnya. Pencarian data di lapangan dengan 
mempergunakan alat pengumpul data yang sudah disediakan secara tertulis ataupun tanpa alat yang hanya merupakan angan-angan tentang suatu hal yang akan dicari di lapangan, sudah merupakan proses pengadaan data primer (Subagyo, 2004, p. 37). Adapun teknik pengumpulan data yang digunakan dalam penelitian Dampak Pembangunan Srambang Park Ngawi terhadap Kehidupan Ekonomi Masyarakat dan Potensinya sebagai Sumber Materi Pembelajaran IPS SD adalah: observasi, wawancara, dan dokumentasi.

Penelitian tentang Dampak Pembangunan Srambang Park Ngawi terhadap Kehidupan Ekonomi Masyarakat dan Potensinya sebagai Sumber Materi Pembelajaran IPS SD dilakukan kurang lebih selama tiga bulan yaitu dimulai bulan Oktober hingga Desember 2018. Adapun tahap-tahap penelitian adalah: tahap persiapan, tahap pelaksanaan, dan tahap penyelesaian.

\section{Hasil dan Pembahasan}

\section{Srambang Park Ngawi}

Srambang Park Ngawi adalah salah satu obyek wisata yang berada di Desa Girimulyo Kecamatan Jogorogo Kabupaten Ngawi. Berkonsep taman hutan asri dan air terjun obyek wisata ini menawarkan keindahan yang sanggup memanjakan mata pengunjung maka tidak heran apabila banyak wisatawan yang datang untuk melepas penat. Letaknya yang berada di lereng Gunung Lawu juga membuat udaranya sangat sejuk. Sejarah munculnya obyek wisata Srambang dimulai pada tahun 1995 waktu itu ada lahar dingin, pohon-pohon hanyut di sungai dan masyarakat banyak yang melihat, akhirnya oleh pihak Perhutani di buka menjadi obyek tujuan wisata dan dibuatkan jalan sampai air terjun. Setelah itu, pada tahun 2017 atas berkat buah pemikiran dari berbagai pihak dalam hal ini pihak swasta, Perhutani, Pemerintah Pusat, Pemerintah Daerah dan masyarakat sekitar akhirnya dibangun Srambang Park Ngawi ini. Pembangunan berlangsung selama 3 bulan dari bulan Oktober hingga selesai bulan Desember kemudian diresmikan oleh Bupati Ngawi Ir. H. Budi Sulistyono pada tanggal 19 Desember 2017.

Pembangunan yang dilaksanakan di kawasan wisata yaitu pembangunan jalan menuju Srambang Park Ngawi, pembangunan pintu masuk yang dilengkapi dengan pos jaga (pos ini digunakan untuk memungut retribusi dari wisatawan), selain itu juga dibangun berbagai fasilitas diantaranya area parkir yang luas, toilet, kamar mandi, mushola, tempat berfoto, rumah makan, jalan berkelok, Taman Joko Tarub, gubug bambu di tepi tebing, Taman Anjasmara, rumah pohon yang kokoh, saung bambu, belik widodari, jembatan rindu, Taman Dewi Nawang Wulan, Taman Dewi Nawang Sih dan taman bukit berbunga. Biaya retribusi obyek wisata Srambang Park Ngawi Rp 15.000/orang belum termasuk sewa tempat parkir. Untuk parkir kendaraan roda dua 2.000 rupiah sedangkan kendaraan roda empat 5.000 rupiah. Pada kawasan wisata juga terdapat puluhan jasa ojek untuk mengantarkan wisatawan yang tidak ingin berjalan kaki terlalu jauh, rutenya dari tempat parkir menuju pos jaga pintu masuk Srambang Park Ngawi maupun sebaliknya, biaya untuk ojek wisata 5.000 rupiah sekali perjalanan. Masyarakat Desa Girimulyo menyambut positif atas dibangunnya Srambang Park Ngawi. Mereka beranggapan bahwa

\section{Ekonomi Masyarakat}

Sumber penghidupan masyarakat di Desa Girimulyo sebelum pembangunan obyek wisata Srambang Park Ngawi pada umumnya adalah petani. Sektor pertanian jenis komoditi yang dihasilkan adalah padi. Pembangunan kawasan wisata Srambang Park Ngawi adalah salah satu bentuk pengelolaan kawasan wisata alam yang bertujuan untuk memberikan manfaat terutama bagi perlindungan, pelestarian serta pemanfaatan potensi wisata dan jasa lingkungan sumber daya alam khususnya pada wilayah hutan lindung Perhutani KPH Lawu DS Drive Jawa Timur. Selain itu, 
masyarakat dapat merasakan manfaatnya secara langsung di sektor kepariwisataan melalui terbukanya lapangan usaha yang menciptakan kesempatan kerja baru serta mampu meningkatkan pendapatan bagi masyarakat.

Penyelenggaraan kepariwisataan juga ditujukan untuk meningkatkan pendapatan nasional dalam rangka meningkatkan kesejahteraan dan kemakmuran rakyat, memperluas, memeratakan kesempatan berusaha dan lapangan kerja, mendorong pembangunan daerah, memperkenalkan dan mendaya gunakan obyek dan daya tarik wisata di Indonesia serta memupuk rasa cinta tanah air dan mempercepat persahabatan antar bangsa. Pembangunan pariwisata juga mendorong dan mempercepat pertumbuhan ekonomi. Kegiatan pariwisata menciptakan permintaan, baik konsumsi maupun investasi yang pada gilirannya akan menimbulkan kegiatan produksi barang dan jasa. Selama berwisata, wisatawan akan melakukan belanja, sehingga secara langsung menimbulkan permintaan (Tourism Final Demand) pasar barang dan jasa. Selanjutnya, final demand wisatawan secara tidak langsung menimbulkan permintaan akan barang modal dan bahan baku (Investmen Derived Demand) untuk berproduksi memenuhi permintaan wisatawan akan barang dan jasa tersebut. Dalam usaha memenuhi permintaan wisatawan diperlukan investasi di bidang transportasi, komunikasi, perhotelan/penginapan, akomodasi, industri jasa, rumah makan dan lain-lain.

Sehubungan dengan pesatnya perkembangan pariwisata, pola pembangunan berkelanjutan tersebut sangat cocok diterapkan karena dapat bertujuan untuk melestarikan keberadaan pariwisata yang ada sekarang ini kepada generasi yang akan datang. Pembangunan pariwisata difokuskan pada tiga aspek utama yaitu ekonomi, sosial-budaya dan lingkungan. Untuk mengetahui besarnya dampak ekonomi yang ditimbulkan oleh suatu kegiatan, komponen-komponen dan fungsi sistem ekonomi beserta pranata lainnya perlu diperhatikan antara lain:

1. Bahwa sistem ekonomi tersusun atas hubungan timbal balik dari pelaku-pelaku ekonomi dan organisasi.

2. Bahwa sistem ekonomi mengatur perubahan dari persediaan bahan mentah menjadi barang jadi.

3. Bahwa sistem ekonomi menentukan distribusi dari barang dan jasa yang diperlukan.

4. Bahwa sistem ekonomi mempengaruhi persepsi ruang mengenai barang dan jasa yang dibutuhkan.

Pembangunan pariwisata mempunyai pengaruh dan hubungan interpenden dengan sektor lainnya, terutama terhadap sektor industri kecil dan kerajinan rumah tangga serta stabilitas lingkungan hidup. Dampak yang ditimbulkan sebagai akibat aktivitas ekonomi sangat tergantung pada sistem ekonomi yang ada di daerah tersebut.

Aktivitas pariwisata akan mempengaruhi model ekonomi yang ada di daerah wisata. Perubahan yang terjadi karena aktivitas pariwisata sangat berpengaruh pula pada struktur dan ekonomi daerah. Kesempatan kerja, pendapatan perkapita maupun distribusinya akan memberikan peluang kepada peningkatan produksi maupun kesejahteraan masyarakat secara keseluruhan. Adanya perubahan kondisi ekonomi masyarakat mendorong komponen-komponen ekonomi untuk merubah lingkungannya sesuai dengan kemampuan daya dukung lingkungan, baik dalam bentuk kelembagaan maupun instrukturnya. Tumbuhnya aktivitas-aktivitas ekonomi baru mendorong pranata-pranata sosial yang ada dalam suatu masyarakat untuk menyesuaikan diri terhadap perkembangan ekonomi yang ada.

Pariwisata merupakan industri yang padat karya karena tenaga kerja sulit diganti dengan modal atau peralatan. Semua sektor akomodasi dikatakan relatif lebih padat karya dibandingkan pada sektor lainnya, sehingga pariwisata sebagai sumber penciptaan lapangan pekerjaan. Pariwisata merupakan sumber pokok dari pekerjaan pada tingkat regional, akan tetapi jumlah dan jenis pekerjaannya bermacam-macam dan berbeda antar daerah dan tergantung pada struktur industri 
pariwisata, khususnya untuk pekerjaan musiman. Hubungan antara pekerjaan dalam industri pariwisata dan pekerjaan rumah tangga harus dipertimbangkan. Apakah pekerjaan pariwisata merupakan pekerjaan pokok atau sementara saja, kemudian begitu pula yang dibahas dalam penelitian ini dengan adanya pembangunan wisata Srambang Park Ngawi maka dampak perekonomian terlihat dari aktivitas masyarakatnya menunjukkan suatu perubahan kearah yang lebih baik, dimana sebelum pembangunan obyek wisata Srambang Park Ngawi aktivitas masyarakat sebagian besar adalah petani, pedagang kecil-kecilan dan karyawan. Namun dengan adanya pembangunan obyek wisata Srambang Park Ngawi masyarakat mendapatkan pekerjaan tambahan (sampingan) untuk menambah pendapatan dan berdasarkan penelitian dikatakan meningkat dilihat dari hasil wawancara.

Pembangunan kawasan wisata Srambang Park Ngawi harus lebih diarahkan dan dipergunakan dalam upaya pembangunan kawasan wisata ramah lingkungan. Pembangunan kawasan wisata Srambang Park Ngawi juga perlu mengetengahkan faktor kewaspadaan terhadap dampak lingkungan menjadi sangat penting, terutama dari kunjungan wisatawan yang tidak terkendali guna memelihara keberlanjutan kualitas lingkungan hidup khususnya dalam menjamin pembangunan dalam bidang ekonomi yang berkelanjutan. Bidang lingkungan hidup, pada dasarnya pembangunan Srambang Park Ngawi adalah memanfaatkan kondisi lingkungan yang menarik. Jadi pembangunan wisata alam senantiasa dalam keadaan baik dan tentu menghindari kerusakan. Perencanaan pariwisata yang baik, teratur dan terarah, secara tidak langsung akan memberikan dampak pada lingkungan yang akan terjaga dengan baik.

Sektor pariwisata merupakan sektor yang potensial untuk dikembangkan sebagai salah satu sumber pendapatan asli daerah. Usaha dalam memperbesar pendapatan asli daerah, maka program pembangunan dan pendayagunaan sumber daya serta potensi pariwisata daerah diharapkan dapat memberikan sumbangan bagi pembangunan ekonomi. Secara luas pariwisata di pandang sebagai kegiatan yang mempunyai multidimensi dari rangkaian suatu proses pembangunan. Oleh karena itu, pariwisata perlu mendapat perhatian yang serius dari pembuat kebijakan dalam negeri dan perancang kesepakatan perdagangan internasional, mengingat pariwisata di masa mendatang merupakan penyumbang besar kesejahteraan ekonomi dunia.

\section{Potensi Dampak Srambang Park Ngawi Terhadap Kehidupan Ekonomi Masyarakat Sebagai Sumber Materi Pembelajaran IPS SD}

Dampak pembangunan Srambang Park Ngawi terhadap kehidupan ekonomi masyarakat ini memiliki beberapa nilai-nilai yang bisa diwariskan kepada masyarakat antara lain:

a. Nilai pendidikan yakni kita mampu mengambil nilai-nilai pendidikan untuk terus belajar menambah ilmu pengetahuan sehingga akan memiliki kehidupan lebih baik lagi di masa mendatang.

b. Nilai ekonomi, yakni kita mampu mengambil nilai-nilai ekonomi untuk bisa berfikir kreatif, inovatif dan mandiri dalam menciptakan kegiatan-kegiatan ekonomi sebagai upaya peningkatan pendapatan untuk memenuhi kebutuhan.

c. Nilai sosial, yakni kita mampu mengambil nilai-nilai sosial untuk bisa membangun solidaritas yang tinggi antar umat manusia.

d. Dengan banyaknya nilai-nilai yang dapat diambil dari dampak pembangunan Srambang Park Ngawi terhadap kehidupan ekonomi masyarakat maka dapat dijadikan sebagai sumber materi pembelajaran IPS SD khususnya untuk kelas IV pada materi pemanfaatan sumber daya alam kaitannya dengan ekonomi masyarakat. 


\section{Simpulan}

Supervisi akademik berkelanjutan dapat meningkatkan kompetensi guru kelas satu sampai kelas 6 dalam menyusun RPP dan silabus di SD Negeri 2 Ngadisanan Kecamatan Sambit Kabupaten Ponorogo. Tahap praobservasi, menunjukkan bahwa kemampuan guru dalam menyusun RPP dan silabus masih dalam kategori kurang nilai rata-rata komptensi dalam telaah RPP kelas satu sampai kelas enam adalah 65\%. Pada siklus I, kompetensi guru dalam telaah RPP setelah diadakan supervisi nilai rata-rata mencapai $80 \%$ meskipun masih dalam kreteria cukup.. Pada siklus II, dengan didakan refleksi dan perbaikan kompetensi guru dalam menyusun RPP mulai terlihat lebih baik terbukti dari nilai rata-rat dalam telaah RPP mencapai nilai $85 \%$ dengan kategori baik.

\section{Daftar Pustaka}

Arman, A. (2017). Upaya Peningkatan Kompetensi Guru dalam Menyusun Rencana Pelaksanaan Pembelajaran Melalui Supervisi Akademik Kepala Sekolah Di SMAN 1 Lembah Melintang Kabupaten Pasaman Barat. Jurnal Manajemen Pendidikan, 1(1), 55-62.

Astuti, R., \& Dacholfany, M. I. (2016). Kepemimpinan Kepala Sekolah Terhadap Kinerja Guru di Kota Metro Lampung. Jurnal Lentera Pendidikan Pusat Penelitian LPPM UM METRO, 1(2), 204-217.

Bungin, B. (2007). Penelitian Kualitatif, Komunikasi, Ekonomi, Kebijakan Publik, dan Ilmu Sosial. Jakarta: Prenada Media Grup.

Hardono, H., Haryono, H., \& Yusuf, A. (2017). Kepemimpinan Kepala Sekolah, Supervisi Akademik, dan Motivasi Kerja dalam Meningkatkan Kinerja Guru. Educational Management, $6(1), 26-33$.

Leniwati, L., \& Arafat, Y. (2017). Implementasi Supervisi Akademik Kepala Sekolah Untuk Meningkatkan Kinerja Guru, 1(1), 325-343. Retrieved from The Value of Pancasila, National Insight, PPKn Subject

Lestari, A. S. (2014). Evaluasi Daya Tarik Wisata Untuk Pengembangan Objek Wisata Alam Kabupaten Ngawi. Universitas Negeri Malang. Retrieved from http://karyailmiah.um.ac.id/index.php/Geografi/article/view/37955

Nachrawie, M. (2017). Sumber belajarlingkungan dalam pembelajaran IPS di SMPN 1 Kusan Hulu Kabupaten Tanah Bumbu. SOCIUS:Jurnal Pendidikan Dan Pembelajaran Ilmu Pengetahuan Sosial, 6(2), 182-208.

Ndapaloka, V., Hardyanto, W., \& Prihatin, T. (2016). Pengaruh Supervisi Akademik Pengawas Dan Kepemimpinan Kepala Sekolah Melalui Motivasi Berprestasi Sebagai Mediasi Terhadap Kinerja Guru Smk Negeri Kabupaten Ende. Educational Management, 5(1), 42-54.

Prihono, H. (2014). Model Supervisi Akademik Berbasis Evaluasi Diri Melalui MGMP Sekolah Untuk Meningkatkan Kompetensi Pedagogik Guru SMK di Kabupaten Wonogiri. Educational Management, 3(2), 126-132.

Ramadhan, A. (2017). Pengaruh Pelaksanaan Supervisi Akademik Pengawas Sekolah Dan Supervisi Kepala Sekolah Terhadap Kinerja Guru SMK Negeri Di Kabupaten Majene. Journal of Educational Science and Technology (EST), 3(2), 136. https://doi.org/10.26858/est.v3i2.3579

Subagyo, J. (2004). Metode Penelitian dalam Teori dan Praktek. Jakarta: PT Adi Subagyo Mahastya.

Sugiyono. (2009). Metode Penelitian Administrasi dilengkapi Metode R\&D. Bandung: Alfabeta.

Trilaksana, A. (2014). Perkembangan Pariwisata Kabupaten Ngawi Tahun 2000-2013. AVATARA, e-Journal Pendidikan Sejarah, 2(3), 440-452. 